\title{
AMCoR
}

Asahikawa Medical College Repository http://amcor.asahikawa-med.ac.jp/

Medical Anthropology (2001) 20(2-3):141-184.

Postmodern midwives in Japan : the offspring of modern hospital birth

Matsuoka, Etsuko 


\section{Postmodern Midwives in Japan: The Offspring of Modern Hospital Birth Etsuko Matsuoka}

Although childbirth is fundamentally involved with the issue of women's bodies, it is also involved with such social values as politics, economics, medicine, and other phenomena characteristic of a particular time and culture. In this article I divide Japanese society and childbirth into pre-modern, modern, and postmodern phases, with special emphasis on the postmodern phase. I use the word "postmodern" to denote visible changes in childbirth and midwifery that began to occur around 1990 -- changes that distinguish it from modern hospital birth. I conclude that postmodern midwifery is a reaction to and a consequence of modern hospital birth, which failed to satisfy a large number of women's needs. In this sense, postmodern midwifery could rightly be said to be the offspring of modern hospital birth.

\section{Overview of Midwifery in Japan}

In Japan, from around the 11th century to the 18th century, when midwifery was not yet an occupation, those attending the birth of a noblewoman and holding her hips were known as koshi-daki (koshi $=$ hips, daki = to hold). During the Edo period (1603-1868), midwifery gradually came to be recognized as an occupation in big cities, but in villages midwifery was not an occupation; rather, women assisted birthing women in mutually helpful ways. Those attending a birth were referred to by various terms, among them sanba (san = birth, $b a=$ old woman) and toriage-baba (taking up-old woman), and their qualifications, training system, and the scope of their work were not officially defined. This is reflected in the fact that, in different regions of Japan, the terms used to describe birth attendant varied greatly. They were, for example, referred to as hara-mon-baba (abdomen-massaging-old woman) in the Kyushu region, heso-baba (umbilicus-old woman) in the Kyushu and Shikoku regions, arai-baba (bathing-old woman) in the Chugoku region, and 
konasase-baba (let bear child-old woman) in Tohoku region. The jobs associated with midwifery ranged from massaging laboring women to cutting umbilical cords and bathing babies. Interestingly, midwives did not necessarily deliver babies.

The Meiji era began in 1868, and medical regulations were issued in 1874 to cover the three major cities of Tokyo, Kyoto, and Osaka. These medical regulations included articles concerning sanba, which specified that a sanba be at least 40 years of age with a license granted after delivering 10 normal births and two abnormal ones in front of an obstetrician. These regulations added that those who had been practicing would be given a provisional license. Similar official notices followed in other prefectures which investigated the personal records of the sanba in their regions, interviewed them and gave them provisional licenses. In 1898, a year before the Japanese government enacted the nationwide Midwifery (Sanba) Regulations, there were 35,945 midwives throughout Japan. However, in 1899 the Midwifery Regulations specified that sanba had to be at least 20 years old and to have their names listed in a registration book upon passing sanba examinations ${ }^{1}$. Thus, the number of sanba dropped from 35,945 to 8,367 (Ishihara 1983). The year after, it somehow rose to 25,049 . $^{2}$ These midwifery regulations standardized qualifications for sanba (which had been variously defined in each prefecture) by establishing training systems, limiting the midwives' scope of work to the handling of normal births, and setting out penal provisions. This sanba license was initially granted only to newly qualified sanba: all those women who had been practicing as sanba prior to 1899 were now doing so illegally although provisional licenses were granted to those sanba who had had previous licenses and to those who wished to practice in areas lacking another qualified sanba, although in the latter case the provisional license was further restricted to a specified village. The licensing of sanba left some birth attendants unlicensed who were referred to as lay or old sanba in contrast with newly registered sanba. In fact, unlicensed sanba persisted into the 1950s in rural areas in Japan. The use of the term sanba to denote midwives continued until 1947, when the term Josan-pu (josan = help birth, $p u=$ woman) was employed officially in a newly enacted law concerning public health nurse, midwife and nurse. ${ }^{3}$

In controlling sanba, the government intended to increase the nation's population; it was particularly interested in ensuring a supply of healthy soldiers. It was thought that, by raising the 
standards of midwifery and prohibiting midwives from any involvement in abortion, it would be possible to make the lives of newborns more secure. In 1876 the first midwifery school based on Western medicine was founded in Tokyo; this school was soon followed by many others across Japan. ${ }^{4}$ Sanba trained in Western medicine were sometimes called "new" sanba or "Western" sanba to distinguish them from "lay" or "old" sanba. In Japan the history of western medicine goes back to the $16^{\text {th }}$ century when Christian missionaries, trying to spread Christianity, also tended the sick. In the Edo period, when the Japanese government restricted contact with the outside world, only the Dutch were allowed to maintain presence at Dejima in Nagasaki Prefecture where they practiced medicine. At the beginning of the Meiji Era, the new government radically shifted its policy to assimilate western medicine, by sending young students mainly to Germany and by hiring medical doctors from America and Europe. Midwifery schools in the late $19^{\text {th }}$ century were often founded and taught by doctors who had studied obstetrics in Germany. The newly educated sanba affected traditional birthing customs in two ways: (1) they tried to spread the idea of cleanliness to avoid infection by abolishing the use of dirty rags for absorption of blood and discharges; and (2) they changed the birth position from squatting to lying down. Licensed sanba (both with and without formal medical education) worked independently, attending home deliveries and keeping close contact with the medical doctors, upon whom they would call in cases of abnormal birth. These licensed sanba formed a local guild, which eventually developed into a nationwide midwifery organization in 1927. Their numbers increased, and those who were successful in big cities enjoyed the same high status, economic affluence, and local authority as did physicians. It could be said that this pre-war period was the prime time for Japanese midwives, for they undertook home births in urban areas almost single-handedly, and, in 1941, their numbers swelled to 62,741 (their numbers attained the largest 77,560 after the war in 1951). By 1998 , their numbers had dropped to 24,202 (see Figure 1). In those pre-war years, sanba were almost all independent in that they were not working for either doctors or institutions.

This golden age continued until Japan lost the Second World War and the health system was radically reorganized under the health reform initiated by General Headquarters. (GHQ refers to the American occupying force). In 1946 the nationwide midwifery organization was dissolved, and in 1948 the educational system for midwives was merged with that for nurses (Ohbayashi 1989). Under 
this new system, which was modeled on American nursing standards, midwifery required three years of nursing education and then one year of midwifery training (by law, midwifery training must last for over six months). The fact that health reform progressed under the supervision of the GHQ, whose health system did not include midwifery, resulted in a lessening of autonomy for Japan's midwives. Interestingly, because there was no comparable profession in the United States, American nurses were surprised to find that Japanese midwives were well-trained and able to perform efficient home deliveries. For their part, Japanese midwives were bewildered by the irrationality to which they were often subjected when GHQ nurses inspected a local midwifery organization. An old Japanese midwife recounted her experience with a GHQ nurse as follows:

After the war an American nurse visited the midwifery organization in my area and taught us how to bathe a newborn baby. She was very young--young enough to look just out of school. She washed a baby doll with soap outside the tub and then soaked it in a small amount of warm water in the tub. We whispered among ourselves: "I would like to see her do that with a real baby. Would soap come off with so little water? A real baby would catch cold with such awkward handling." But we listened to her without any complaint because that was what we were told to do by the winning country.

It was in this manner that GHQ health reform progressed, and it can be imagined that similar encounters would have occurred in many other local midwifery organizations. According to my interviews with old Japanese midwives, GHQ nurses did not directly tell them to stop performing home deliveries; however, they did emphasize the importance of hygiene and, by implication, institutional birth (Matsuoka 1991).

The rate of home birth, which was still high prior to 1950 due to the postwar baby boom, decreased rapidly from 97.6 percent in 1947 to 49.9 percent in 1960, to only 3.9 percent in 1970 (see Figure 2). The move from home births to institutional births served to reduce the number of midwives (now called josan-pu) working independently from 86 percent in 1962, to 49 percent in 1975, to only 8.6 percent (2,078) in 1998 (Kosei-tokei-kyokai 2000:178) (See Figure 3). ${ }^{5}$ As the diminishing number of home births dispossessed independent midwives of their jobs, small numbers of them survived by 
setting up their own maternity homes (birth centers); the rate of maternity-home birth peaked at 12.9 percent in 1965 (see Figure 2). ${ }^{6}$ Others, however, ceased being independent to work in hospitals, to take up family planning, or to make home visits to care for newborn babies. ${ }^{7}$ As they aged, most independent midwives stopped performing deliveries, with the result that their numbers and presence in the community soon became negligible. Meanwhile, newly graduated midwives went directly into hospitals; from 1976 on, their number exceeded that of independent midwives. At the beginning of the 1980s, when some pregnant women wanted to give birth naturally through the Lamaze method, which was very popular, they turned to those independent midwives who were running their own maternity homes. These midwives were already in their sixties and seventies, but they were still very eager to assist in births. Thus the Lamaze method revitalized the aging generation of independent midwives, who by the end of the 1970s had been very much in the background. Although by law midwives, like physicians, were entitled to have their own practice, those who had worked in hospital did not, with rare exceptions, take advantage of this, possibly because birth outside the hospital had come to symbolize lack of development and was, in any case, not in demand. Another reason could be that, without institutional protection, midwives were reluctant to take full responsibility for their patients (malpractice suits were not uncommon).

A slight change, however, occurred around 1990, when some midwives working in hospitals decided to become independent, setting up their own maternity homes in various communities. Alternatively, several hospital-employed midwives might organize an annual event in order to appeal to women and to inform the general public that they were there to serve women in pregnancy and birth. If there is one common motivation behind these actions, it is probably the awareness that midwifery was in danger of diminishing both in the community and in the institutions. In the community independent midwives were already inactive due to old age, were not recognized by the public, and had not passed their skills and experience on to a younger generation of midwives. In hospitals, women in labor did not notice the existence of midwives because they could not differentiate them from the nurses. In other words, midwives realized the strong need to be recognized by the public and to revitalize both their self-awareness and their public presence. ${ }^{8}$

The postmodern midwife that I discuss here can be either independent or employed by a 
hospital, although the ones I interviewed all happened to be independent. They are distinct from traditional independent midwives in terms of their age, their way of thinking, and their way of practicing. They are also quite different from most hospital-employed midwives. Hospital-employed midwives comprise $83.6 \%$ of Japan's 24,202 working midwives while only 8.6\%, 2078 in number, work independently; of these 2078 midwives it is estimated that only 3- 400 are actively engaged in delivery and the number who fit the definition of postmodern are even less than that. Based on the distinctions between pre-modern, modern, and postmodern that I will delineate later on, I will show that traditional independent midwives represent pre-modern society, hospital-employed midwives represent modern society, and postmodern midwives represent postmodern society.

\section{Methods}

In this article I focus on the narratives of seven midwives whom I consider to be practicing in a new style. I started interviewing midwives at the beginning of the 1980s. First, I interviewed those independent midwives who reactivated themselves when the Lamaze method became popular; second, in order to familiarize myself with the historical transitions of Japanese midwifery, I interviewed very old ex-independent midwives or second- or third-generation independent midwives; and, third, I interviewed those midwives who had recently set up their own maternity homes or birth centers after having worked for some years in hospitals. During those twenty years I also visited hospitals to observe deliveries of various kinds and talked with midwives in institutional settings. Depending on the situation, some interviews were taped while others were written down. As I collected and recounted these interviews over the years, I came to recognize that new types of midwifery practices had been emerging since around 1990, although at that time it did not occur to me to categorize them as "postmodern." However, upon being introduced to Robbie Davis-Floyd's notion of "postmodern midwifery," I realized the usefulness of interpreting these new types of midwifery within a framework of pre-modern, modern and postmodern eras and styles. I tried to be attentive to the information provided by midwives whose unique activities were talked about in meetings, in midwifery journals, or in conversation with other midwives.

Since around 1995, driven by feelings of crisis that were shared by midwives all over Japan 
(see note 8), leading midwives organized events in several major cities in order to demonstrate to pregnant women (as well as to mothers and their partners) how they could offer them childbirth in a relaxed and comfortable atmosphere. In some cities, midwives paraded on the street to remind the public that they were there and that they could help women give birth. Some women became "free-independent" midwives -- people who were not affiliated with any hospitals or maternity homes but who helped other midwives with home deliveries when needed and who set up their own birth centers upon leaving hospitals. What these women had in common was the awareness that, in hospitals, because they had been relegated to the status of doctor's assistant and/or lumped together with nurses, they had been invisible. They believed that they had to regain their identity by demonstrating their skills to the public. This strong need to be recognized as midwives is, I suggest, what made them look for new ways of practicing midwifery, whether in hospitals or independently.

I phoned some of these midwives to see whether they would agree to my interviews. These new Japanese midwives live in many parts of the country; for practical reasons, I concentrated on those who were geographically close to my area (eastern Japan). Their location, age, and type of practice are summarized in Table 2.

In analyzing the ideas and activities of these seven midwives, I hope to illustrate their difference from traditional independent (premodern) midwives as well as from hospital-employed (modern) midwives. The emergence of these new postmodern midwives, which was generated both by their awareness of crisis and the demands of women, reveals the tensions within the existing midwifery system and between midwifery and obstetrics in Japan.

\section{Childbirth in Pre-modern, Modern, and Postmodern Societies}

In The Coming of Post-Industrial Society, Daniel Bell (1973:116) characterizes societies as pre-industrial, industrial, and post-industrial in order to illuminate essential differences in their social structure. According to this conceptual schema, the economy of pre-industrial societies is primarily based on agriculture, of industrial society on manufacturing, and of post-industrial society on industries such as finance, communication, education and so on.

I take the position that a society is embodied in various aspects of social and cultural life, 
including modes of production: we can only interpret society through its aspects--economy, education and others--and of these, production is among the most salient. For instance, in modern society machine manufacture extends its influence into other spheres, transforming and reorganizing them so that they are in line with the values of machine production. In other words, machine manufacture is not just a mode of production but a dominant symbol that can induce changes in every sphere of society: it is through such symbols that we construct social life. In the following discussion I use the terms "pre-modern," "modern," and "postmodern," instead of industrial, to designate societal types with the understanding that "modern society" is equivalent to Bell's "industrial" society.

Postmodern society, as the term is used in this paper, appears during the phase of advanced capitalism during which factory production ceases to be a dominant symbol, giving place to the management of information, knowledge, and services. The terms "postmodern," "postmodernism," and "postmodernity" are used in many different fields and carry multiple and contested meanings (Bauman 1992). "Postmodern" can be taken to mean "end of modernity," "after modernity," "anti-modern," and/or "high modernity" (Jameson 1984; Giddens 1990; Bertens 1995; Turner 1993). Alternatively, it can connote the lifestyle of the consumer society that appears during late capitalism (Featherstone 1991). There is not one definition upon which all agree; nevertheless, there is an understanding among those who use the term "postmodern" that contemporary society has entered a phase characterized by multiplicity, diversity, and a fluidity of information and boundaries -- a phase that did not characterize modern, industrialist society. I use the term "postmodern" as an ordering device (Bell 1973:119) to enable me to understand the changes occurring in the contemporary cultural arena of Japanese childbirth and midwifery.

Table 1 illustrates how Japanese childbirth shifted during the pre-modern, modern, and postmodern eras. In Japan, modernization is usually said to have occurred since the late 19th century; however, it was primarily during the period of rapid economic growth between 1955 and 1973 that Japan underwent a full modernizing process -- a process that continued until the end of the 1980s. Thus modern refers to the years from 1955 to the 1980s; pre-modern the years prior to that period; and postmodern to the years following the modern era. This classification is for analytical purposes only; it is not an attempt to engage in rigid periodization. 
As the mode of production shifts from home-based agriculture and handicraft to mass production in the factory, there is a concomitant shift in the mode of reproduction, from giving birth at home to giving birth in hospital. When the economy further shifts from agriculture or manufacturing to service and information industries (e.g., finance, communication, health, education, etc.), the reproductive mode becomes multiple and allows for personal choice (Matsuoka 1995). The type and status of birth attendants also change: pre-modern society produces both lay and licensed midwives; modern society produces licensed midwives who work within institutional settings; and postmodern society facilitates the emergence of midwives who are highly mobile, flexible, and egalitarian.

Brigitte Jordan (1993) has shown how a culture's definition of birth shapes its treatment of the birth process. And Robbie Davis-Floyd (1992) has described the influence of cultural paradigms on practitioners' and women's interpretation of the meaning of events in labor and birth. In pre-modern society birth is a normal part of women's lives and an occasion for ritual and for mutual help; in modern society it is a medical and technological event that takes place in hospitals; in postmodern society it is often viewed as an expression of an individual's lifestyle and personal choice. Preferred positions for birth change according to whichever paradigm of birth is dominant: pre-modern $=$ vertical, modern $=$ horizontal, postmodern = a more active, free position. In pre-modern society birthing women are seen as neighbors and familiar faces, in modern society as anonymous patients, and in postmodern society as consumers-cum-clients. And birth complications, in pre-modern society, are seen as random, uncontrolled misfortunes or divine punishments, in modern society as unpredictable accidents, and in postmodern society as risks that can be calculated and managed to minimize the chances for unknown to happen in a birth process.

Although childbirth is, physiologically, relatively constant, it is perceived differently within different contexts. Similarly, midwifery -- the customs, art, and meanings surrounding persons who assist in births -- also varies from context to context. In what follows I will discuss childbirth and midwifery within the pre-modern, modern, and postmodern eras, respectively.

\section{Giving Birth in Pre-Modern Japanese Society ${ }^{9}$}

In Japan, the fact that more than twice as many midwives practiced during the pre-Second 
World War period as during the present era might suggest that those midwives' views on childbirth set the tone of birth in pre-modern (pre-war) society. Indeed, in 1930, 90 percent of sanba had received medical training (that is, they had either passed examinations or graduated from authorized midwifery schools which was a level of education and knowledge considerably higher than the norm for women of that period of 6 years of primary schooling; at that time, midwife or teacher was almost the only professional job open to a woman. Moreover, 30 years after the enactment of nationwide Midwifery Regulations, the prestige of licensed midwives was such that they were given, by the urban public, a status as high as if they were women doctors. ${ }^{10}$ However, their attitude towards childbirth, which could be described as medically formed, did not predominate over folk ideas of childbirth among the Japanese populace at large: the gap, in terms of education, prestige, even social class, between the educated midwives and the large numbers of village women attending births was large. One reason for this is that educated midwives mainly served women in urban areas while the majority of village people either relied on experienced neighbors or gave birth totally unassisted. In 1934 there were 2,351 villages that had no midwives or doctors (Teikoku-gikai shugiin iinnkaigiroku 1934:123 [Records of Committees of the House of Representatives of the Imperial Diet]). In what follows I will illustrate how, in pre-modern society, giving birth was deeply embedded in village customs.

This account was given in 1931 by a 74-year-old woman and her lawyer when she was fined for the illegal practice of midwifery (Shirohto no sanji toriagekoui ni tsuite 1932). This woman was found guilty of having helped with six deliveries between January and August 1931 and for having partaken of celebratory feasts after each birth (the court interpreted these feasts as rewards for assisting in births). Her lawyer appealed this decision to the Supreme Court, saying that it utterly disregarded the village situation; however, this appeal was eventually rejected and the ruling was finalized. The lawyer's attempted refutation was based on two points. First, the lawyer had stated that the woman had delivered the placenta, cut the umbilical cord, and bathed the baby but that there was no evidence that she had helped the infant come out of the mother. As the 1899 Midwifery Regulations do not define midwifery, the lawyer contended that it was not right to judge that her behavior had violated it. From what the lawyer wrote in his document it is apparent that, in this particular village, women gave birth to a babies by themselves and people assisted only after the baby 
was out (this was probably because people thought that a baby could come out by itself). This attitude was not uncommon in villages in those days. In this village an old woman (e.g., the laboring woman's own mother or mother-in-law or any woman with experience) generally looks after a baby that has already been born. If this was the attitude held by the villagers (i.e., that giving birth by oneself and getting somebody's help afterward was what birth was about), then giving birth was an occasion for labor exchange or mutual help rather than for something as formal as midwifery. In those days, when women gave birth to many children, birth was part of everyday life, and almost all women gave birth and helped others do so. Because cutting the umbilical cord, clearing the placenta, and washing the baby were essential to each birth procedure, the ruling that these acts violated midwifery regulations must have surprised them considerably. What we would now consider to be an important part of midwifery was conducted by laboring women themselves, and peripheral work (like disposing of the placenta and caring for the baby) was shared by other women in the village. In other words, the profession of midwifery was not yet differentiated from women's daily activities (which included harsh labor in the field and at home as well as giving birth and helping others do so).

Second, the lawyer said that many old women in this village helped women give birth as a matter of mutual aid rather than as an attempt to make money. As the old woman had said in her defense: "In my village, neighbors give a helping hand to each other in childbirth." The lawyer also added that it was a traditional custom in Japan to invite villagers for a naming ceremony and feast on the seventh day following a birth. Thus, the feasting should be considered a ritual occasion rather than a reward for midwifery as those invited, including the old woman herself, gave celebratory gifts to the new mother. If attendance at such feasts were to be taken as a material reward for midwifery, the lawyer argued, then almost all women in remote villages would have to be punished for violating the midwifery regulations.

This court case vividly illustrates how childbirth was looked upon by villagers in pre-modern society. First of all, giving birth was, in their minds, something a woman should do by herself, with the help of others coming only after its completion. Second, giving birth was a communal occasion of mutual help and subsequent feasting -- comparable to events such as marriage, funerals, and seasonal festivals -rather than an incident to be perceived in medical terms. In pre-modern society birth was part of 
women's everyday lives, and it was something they experienced far more often than did their modern or postmodern counterparts. It is most probable that this old woman knew that attending birth was now against the regulations but she would not be convinced why their birth habits violated them because the distinction between acting as a midwife and helping out during birth would simply not make sense to them

As for complications of birth, the lawyer commented: "Since childbirth is one of the hardest tasks for women, they pray to gods and spirits of all kinds ... and once it turns out to be difficult, the most experienced and skillful woman is called upon to help it finish easily" (Shirohto-no sanji toriagekoui ni tsuite 1934:18). In pre-modern society, easy birth was something that was prayed for, and risk could be neither predicted nor prevented. Whether a birth would end with ease or with difficulty was considered to be a matter of chance -- uncontrollable and random. Difficult birth was taken as a misfortune or punishment from a god or spirit -- something beyond human control.

\section{Childbirth in Modern Japanese Society}

Childbirth in modern society is most explicitly expressed in hospital birth, which stands as an example of the industrialization of the medical sphere (just as removing the production of goods from the home into the factory stands as an example of the industrialization of the economic sphere). With regard to reproduction, the drastic move from home to hospital was accelerated between 1955 and 1975, paralleling the rapid economic growth of the postwar period in Japan. The rate of hospital (including clinic) birth increased from 15.4 percent in 1955 to 91.6 percent in 1975 . This was also a period during which there was a radical shift in the way childbirth was conceptualized and, in turn, midwifery moved to the hospitals and came under the supervision of doctors. One of the biggest forces behind this radical shift was, as I have said before, the Americanization of birth that was initiated by the GHQ and subsequently adopted by university medical staff (who learned about surgical methods relating to birth in American university hospitals). ${ }^{11}$ In what follows I discuss how the shift in the way childbirth is perceived came about during this period of rapid modernization. I focus mainly on the change in the attitude of obstetricians, because this best epitomizes ideas about modern birth. This 20-year period of rapid modernization was a time during which the professional 
skills and status of midwives were fragmented because these women were subordinated to doctors and hospital technology (Matsuoka 1999). During this period, the traditional attitude toward birth was replaced by a more interventionist attitude.

In 1950 a famous obstetrician at Japanese Red Cross Hospital wrote: "If an obstetrician relies on cesarean section to deal with a difficult case, he should profess himself to be a surgeon or surgical obstetrician rather than an obstetrician. If he identifies himself as an obstetrician, he should think like one. He should keep in mind that the fetus should pass through the natural birth canal, and it is only in an emergency that it should be delivered from the abdomen" (Kuji 1955:70). He also worried that if birth tended to be conducted by obstetricians, then there would be many more cases of the use of anesthesia, episiotomy, and forceps. This remark represented the attitude of most obstetricians of this time; birth should progress naturally, and normal birth belongs in the realm of the midwife rather than the obstetrician. Kuji and many others guaranteed not only the autonomous practice of midwives, but also the limited use of medical intervention (assuming the birth went naturally). Most obstetricians of this time did not think of meddling with a normal delivery because they believed that obstetrical technology should be used only when it was medically necessary. For example, the cesarean section rate of Tokyo University Hospital between 1927 and 1945 was 0.625 percent, rising to 2.17 percent in 1955 and then to 4.07 percent in 1960. In a round table talk held when the cesarean rate in Japan was around 2 percent, obstetricians agreed that "in Japan [the] cesarean section rate will not rise more than 5\%" (Shinoda 1957:61). This remark, when looked at in light of the 12.6 percent cesarean rate in 1996, shows that, in 1957, obstetricians felt very little need to intervene in the birth process.

In the 1950s, the use of forceps or cesarean was strictly limited to cases that met specific criteria. For example, in a university hospital, if a young staff member used forceps while his professor was away, then he was asked many detailed questions upon the professor's return. Usually his mentor would reprimand him, saying, "it was a too quick decision. You could have waited a bit longer" (Iwata 1968:94). An old obstetrician whom I interviewed talked about the situations in university hospitals around 1955: "If I felt the need to do a cesarean section at that time, I had to phone my professor--even in the middle of night--to explain how cesarean section was indicated. [l] had to get his permission first." According to him, in the 1950s young obstetricians were trained to see with their 
fingertips, especially when they did internal examinations. Fingers were all they could use to get information, so they were told to examine as if they had eyes on the ends of their fingers. These attitudes not only made up for the lack of technology, but they also prevented its abuse by ensuring that it was not used unless medically indicated. The use of obstetrical measures was thereby guaranteed to be restricted to the relatively small numbers of clinically complicated deliveries.

However, around 1960 a new attitude emerged among obstetricians, who began to consider it more important to try to ensure the life of the newborn than to restrict the use of medical means. At a round table talk held in 1961 one obstetrician said: "We should not forget about natural vaginal delivery. If we feel confident dealing with breech birth, there should be no need for c-section in breech birth." To this, another obstetrician responded, "Indeed vaginal birth is the norm for obstetricians, but I believe delivering a baby alive is more important than abstaining from c-section and doing vaginal delivery ... So if I was asked to save the life of a fetus in breech birth, I tend to rely on c-section in primiparas" (Yamamura 1961:39). Traditionally, the breech birth did not medically indicate the need for a cesarean; however, when obstetricians were primarily concerned about the physical condition of the fetus, they felt it easier to rely on cesareans to secure its safety. In this way cesareans gradually became routine measures for breech delivery.

Indeed, some of the obstetricians at that time were worried about the recent increase in the use of forceps and cesareans, and they attributed it to the development of antibiotics and anesthesia as well as to the increasing number of young obstetricians who did not know enough about normal delivery. In 1960, these mixed feelings and attitudes towards birth were evident in Japanese medical journals. For example, one obstetrician said: "The principle of obstetrics is to make birth normal, to watch closely so that it does not become abnormal; but the present medical fee is set in such a way that abnormal birth, with its many interventions, produces more money for doctors" (Moriyama 1961:101).

However, by the end of the 1960s traditional attitudes were gradually being replaced with new approaches, in which, rather than refraining from the use of medical measures, doctors tried to make the most of them. The idea that the use of cesareans should not be expanded or that young doctors don't understand normal delivery disappeared from the pages of obstetric journals, which now 
featured medical electronics. Obstetricians were enthusiastic about this. As one of them said: "As it is impossible to keep extensive records of labor by having somebody always at the bedside, I purchased an electronic fetal monitor when, with much anticipation, it was released on the market (Yamamura 1966:169). When the electronic fetal monitor was introduced into the birthing room, it gave obstetricians more opportunity to predict or diagnose fetal distress and therefore to augment labor with oxitocin in an effort to speed up the birth, with the result that oxitocin use was no longer restricted to abnormal cases (e.g., the woman being long overdue or experiencing prolonged labor). Now it was not unusual to use a drug in order to begin and to complete labor within certain hours of a given day. This shows that the use of one form of technology leads to the use of another. Interventions such as episiotomy, induction, and acceleration, which were rarely applied in the 1950s, were being applied to the majority of births in the 1970's. In other words, obstetrics, which had been only restrictively applied to abnormal birth in Japan, now took over normal birth from midwives, and obstetrical intervention came to be considered a necessity for all women experiencing pregnancy and birth.

In 1974, one obstetrician noted that it was the ultimate ideal of obstetrics to control birth by determining the onset and the end of labor and delivery while ensuring the safety of mother and baby (Iwasaki 1974:166). Another obstetrician wrote: "With labor-adjusting means, I can assemble birth basically on Mondays, Wednesdays, and Saturdays and reduce the number of birth events at night and on Sundays. In this way I can introduce order and efficiency in nursing and paramedical sections. . . and in administration, the laboratory and the pharmacy as well. The workload being almost uniform depending on the day of the week, the staff can handle work with predictability and rationality" (Kozuka 1975). It seems that obstetricians measure the progress of obstetrics according to their ability to control unpredictable births. Thus, planned birth or daytime birth was considered to mark the peak of obstetrical progress, the benefit of which, obstetricians believed, could finally be enjoyed by pregnant women. Technological progress in obstetrics appeared to reach a peak in the late 1970s.

However, this age of great obstetric progress, in the eyes of obstetricians, was seen differently by midwives. One midwife, remembering the situations she had experienced, said: 
Childbirth around 1965 was terrible. The hospital where I worked relied heavily on forceps, and, as midwives are trained to work under doctors, I couldn't say no if I was told to carry a laboring woman to a delivery table, even when I knew that it was too early. Young doctors wanted to practice using forceps. When a woman is around 8 centimeters open, we put her on a delivery table and give her an accelerating drug, but it doesn't work always. Then, a doctor inserts forceps and drags a baby out when the mother is not contracting at all. She is in a state of utter shock. It is more shock than pain. Violence! I can't think of any other word. (Matsuoka 1995a:140)

At a round table concerning maternal mortality in Japan, a midwife explained why it began to increase after the Second World War: "Because of hospital birth, the quality of antenatal care for pregnant women went down. As midwives are now stationed in hospitals, they can no longer reach out and give individual care to women in the community" (Itoh 1961: 19). In contrast, many obstetricians at the round table assumed that the high rate of maternal death could be attributed to home birth with midwives in attendance. However, one obstetrician mentioned the negative side of hospital birth: "Compared with midwives attending home births, midwives attending hospital births don't stay with laboring women throughout, so women panic and lose control due to intense pain." In other words, it was difficult for midwives to maintain their art and skills in hospital settings because they had to give up their autonomy once they were placed under doctors.

There is another issue that rose to the surface due to the new emphasis on hospital birth: the newborn baby. In 1965, one obstetrician said: "Come to think about it, newborn babies demand a great deal of care. . . They cannot call for help. They cannot live without somebody's help. But there is hardly anybody to look after them in hospital" (Kinoshita 1965:30-31). In Japan at the beginning of the 1960s, the obstetric ward was considered by the authorities as a place for mothers. Nursing staff was assigned only according to the numbers of mothers and so there were, officially, no nurses or funds available for the care of the newborn babies. This was not a big problem until around 1960, when the number of institutional births rose to almost 50 percent. Then newborn babies suddenly came to the attention of medical staff, who now saw them as independent beings demanding care as intensive as that demanded by seriously ill patients. In 1965, one doctor commented: "It is only 
recently that newborn babies came into our sight. Years before we treated them as mothers' belongings because more than 90 percent of them were born at home" (Tsuno 1965:39). As almost all babies were born and bred far away from doctors, it was not surprising that the latter knew little about newborn babies and even less about the degree of care that was needed just to keep them alive. From this, it is evident that home births allowed mother and baby to be treated as more or less one unit, while in hospital births that was not possible, because mother and baby were kept apart. In this sense, hospital birth, by separating mother and baby, brought about the "discovery" of newborn babies as independent beings.

The consequences for midwifery of the modernization of birth are significant. First, hospital birth differs from home birth. Like any institution that seeks efficiency, the hospital is organized around cooperation and division of labor (Nakaoka 1971). Following from this, the tasks associated with hospital births are divided among different people. Thus midwives who work in hospitals are trained to concentrate only on particular parts of the birth process. Pre-modern midwives managed the entire process of birth from the beginning of pregnancy to the end of the postpartum period.

Hospital-employed midwives are like factory workers who are expected to concentrate only on what they have been assigned to do rather than on the whole process of production. Thus both birth and midwifery are fragmented in the modern hospital. Second, the introduction and routine use of new technologies (such as fetal monitoring and ultrasound) made the division of work quite obvious, with doctors concentrating on the most crucial work, thereby marginalizing midwives, leaving them only relatively peripheral jobs (Nakaoka 1971). Moreover, these peripheral jobs (such as setting up machines and other equipment to be used readily for doctors, bathing the women after birth, helping to change clothes and so forth) tend to be simple and repetitive in order to increase the efficiency of the whole system. In this way midwives tend to be deskilled within institutional settings, being constantly assigned minor pieces of work. This process may be referred to as the proletarianization of the professions, or the Macdonaldization of labor (Turner 1995; Ritzer 1996). The hierarchy of the hospital places doctors over and above midwives, giving the former the power to assign peripheral jobs to the latter. Third, the idea that normal birth requires obstetrical intervention, along with the idea that normal birth falls within the scope of obstetrics, deprived midwives of their prime function. If it is 
thought that all births are better managed by medical intervention, that is, that normal births can be improved by medical measures, then it follows that home births which do not employ medical measures are lower in quality than hospital births. This view places hospital at the top of a safety scale and birth by midwives or at home at the lower end. The rationale behind this type of hierarchical thinking is that childbirth managed by technological measures is better in quality than that without any (Davis-Floyd 1992).

As has been illustrated, obstetricians believed that the increasing use of technology was an indicator of the progress of obstetrics and, thus, of the increasing quality of care of women in labor. The dominant paradigm of science and technology functioned to exclude midwives and to obscure their role. Some midwives strove to continue in mainstream obstetric practices by subsuming their identities as midwives in a new role that tried to imitate that of doctors, while others attempted to define midwifery care as something distinct from and alternative to technological interventions.

\section{Toward the Postmodern: The Natural Childbirth Movement in Japan}

Although the progress of obstetrics first culminated in planned birth and the full utilization of available technology, the next development involved the natural childbirth movement of the late 1970 s. Although it seemed that birth had become something that obstetricians could control, it soon became clear that women were not satisfied with it. Letters appeared in newspaper columns from parents whose babies had been damaged or lost, possibly by induction or acceleration. These parents expressed distrust of the notion of planned delivery. In a newspaper, one parent wrote: I want to complain about the birth of my child who was born in asphyxia by induction two weeks earlier than the due date. The baby was resuscitated by oxygen but became disabled. In my neighborhood there are six disabled children who were born in the same obstetric clinic. . . Is artificially induced labor really harmless? The health authority in my area did not respond to my complaint. When it comes to medical matters, administration as well as other doctors just shut their mouths and do not touch them. I hope the health authority takes some measures to prevent the recurrence of this kind of unfortunate case" (quoted in Matsuura 1975:47). 
To this a doctor responded by saying: "Anesthetic delivery and artificially induced labor have, if handled properly, good effects on mother and baby. These methods have been developed after so much effort by many doctors and should be looked upon as the best of modern obstetrics. They are used in order to bring about easy birth. Labor is the same whether it is natural or induced artificially. ... I give intravenous to all laboring women in my clinic not only for acceleration but for nutrition (quoted in Matsuura 1975:48). The gap between how laboring women regard birth and how doctors regard it is very wide.

As if to rebel against this obstetric atmosphere, women active in the women's liberation movement, who happened to be of reproductive age, learned the breathing techniques of the Lamaze method and passed them on to other women. Emerging in the late 1970s, the Lamaze method heralded the beginning of the natural childbirth movement in developed countries, and this gave aging independent midwives a chance to revive their careers. In Japan, the Lamaze method was generally understood (1) to be a way of alleviating pain by learning specific breathing and relaxing techniques; and (2) to be a way of giving birth that involved the attendance of a male partner. Thus, it is possible to detect two meanings behind this movement: first, it entailed a backlash against the medicalization of birth; and, second, it entailed the reorganization of the relationship between men and women.

In 1985, three fashion magazines for pregnant women made their appearances and contributed to the commodification of birth. Pregnant women, who had previously been socially invisible, were now constructed as active consumers. The redefinition of pregnancy and birth in terms of consumption brought about variations in methods of birth (e.g., active birth, water birth, etc.), which appeared like new goods on the market. Following from this, some obstetric hospitals and clinics adopted these new methods and/or renovated rooms, buildings, and hospital meals in order to differentiate themselves from other birth places.

Statistically, hospital birth continued to increase, from 95.7 percent in 1980 to 98.7 percent in 1989. For this reason, I regard the 1980 s as part of the modern phase. It paved the way for the postmodern period because the wide media coverage of the Lamaze method, together with the consumerization of pregnancy, provided people with the chance to recognize the existence of alternatives to hospital birth. 


\section{Postmodern Birth and Postmodern Midwifery in Japan}

Influenced by the second wave of feminism, low birth rates, and the commodification of pregnancy and birth (which produced abundant information), some women became more vocal about where they wanted to give birth. In concert with this, the providers of birthing care (i.e., midwives and doctors) went in search of ways to deal with this new demand. As for hospital-employed midwives, some left the institution to become independent while others stayed to challenge the hospital by introducing the free-style birth position and/or midwife-run antenatal services.

In what follows I focus on seven independent midwives whom I consider postmodern (see Introduction, this volume). They started their own practices between the end of the 1980 s and the beginning of the 1990s (see Table 2). It is very difficult to describe their common characteristics and to include them under one category because their types of practice vary so widely. However, this fact itself makes them postmodern, as it shows that they practice according to the needs of each local area and the skills and resources they can personally offer rather than according to a rigid formula. Although their practices center around antenatal check-ups, delivering babies, and supporting breastfeeding and childcare, they are also very active in holding concerts, seminars, informal parties, meetings, and classes for mothers and babies. They also maintain strong ties with other midwives and doctors so that they can cooperate and support each other in times of need. I now go on to discuss these postmodern midwives in terms of nine specific characteristics.

\section{Training through exposure to a variety of working environments. Before becoming} independent, Japanese postmodern midwives work within different contexts and in different places. For instance, besides working as a midwife in the hospital, some of them apprenticed to traditional independent midwives or worked as nurses in neonatal intensive care units (NICUs) or operating theaters. Others had been married, experienced birth, and raised children themselves or had taught at nursing schools. These various backgrounds gave them the opportunities to view midwifery from the outside, providing them with the reflective distance they needed in order to situate their profession within the broader medical system. According to one postmodern midwife: "I became a midwife 
because I like newborn babies. I worked as a nurse in the NICU for six months. If you want to see a tiny life, you think you can look at it after birth, but then it's too late, something is missing. So I wanted to have experiences with premature babies." Another one commented: "While working in the operating theater, I learned doctors' points of view and how to deal with them. The things I learned there, like how to use medications or how to resuscitate, are very helpful now." Thus, one characteristic shared by these seven postmodern midwives is their ability to take a detached view of midwifery and place their work in wider context.

2. Experiences in high-technology medicine. One midwife offered the following account:

The hospital where I worked had more than a hundred high-risk deliveries a month, so I learned almost everything about management of birth. If a doctor tells me to accelerate a labor, I can speed it up, much to his delight; and if he tells me to let a woman deliver by a certain time, I can make her do it without too much strain. And if the baby gets too much stress, I can resuscitate it. But in my mind I felt this shouldn't be the way. I had this basic feeling that the baby was distressed because of all this. Midwives my age have experienced high-tech medicine. We've seen so many ruined births in hospitals.

Another woman said, "I saw baby after baby delivered in distress and wondered why we had to meddle so much in birth. I came to distrust the way we treated babies because they often seemed to need more medical treatments just because we intervened so much."

When these midwives started working in hospitals in the late 1970s and early 1980s, technologies such as ultrasound and fetal monitoring were already in use, and perinatal medicine like NICU care was widely available. The women interviewed received their early training in this already high-tech environment and learned to master technological interventions of all kinds. However, they were aware that these very interventions often increased the risks surrounding birth and that this, in turn, led to the need to apply still more interventions. These midwives felt conflicted and stressed because they were conscious of the limits of hospital birth. 
However, this does not mean that they deny the value of high-tech medicine per se; rather, they are confident and even proud of their ability to use this technology and to have it under their control. They believe this is what differentiates them from traditional independent midwives who, though quite experienced in handling births, lack this additional skill. Technological literacy is important to them because it enables them to communicate with obstetricians on an equal basis by referring to objective data and using a common technological language. Postmodern midwives are not against technology; rather, they are for using it only when it is clear that it will benefit mother and baby.

3. A holistic focus. According to one postmodern midwife: "Birth does not occupy a central place in my work." According to another: "If you focus your energy purely on delivery care that's the same as what happens at the hospital, where, when birth is over, everything is over." In the modern hospital the most important thing is to complete delivery safely without regard for whether a woman feels great pain in the perineum or whether she has swollen breasts during the postpartum period.

In contrast with this delivery-centrism, the scope of postmodern midwives is quite wide; it includes breastfeeding support, the treatment of mastitis, childcare support, and consultation regarding sexual relationships after birth as well as community-based activities such as organizing a support group for disabled children, having a tea party for women in reproductive age, holding a lunch party for mother and baby, and so on. One of the midwives even restricts her work to mainly antenatal and postnatal care, leaving delivery itself to hospitals or other independent midwives. These women do not go along with the common idea that a midwife's job is simply the delivery of a baby; rather, they focus on dealing with women's reproductive lives as a whole (although they do acknowledge the fact that delivery is the most conspicuous part of their work). One midwife said: "While at school I learned that a woman's life is a continuum, but in hospital delivery the focus is just on delivery and everything is piecemeal and fragmentary." This division of work pervades the hospital, depriving midwives of the ability to understand the whole process of pregnancy and birth. Postmodern midwives, freed from delivery-centrism, are trying to reclaim the ability to provide women with flexible and continuous support. 
4. Women-centered care. In general, the midwives whom I interviewed tended not to take the initiative with regard to childbirth--an attitude quite different from that of independent midwives in the 1980s (who played a major role in assisting in the Lamaze method of birth). At that time, midwives taught pregnant women specific breathing and relaxation techniques in order to facilitate easy births. These women believed that part of being a professional midwife included being a teacher. As Fiedler (1997:172) writes: "The midwife who owns and operates her own freestanding clinic, like the obstetrician in the hospital, assumes the role of sensei (suffix for respectable position, synonymous with teacher but literally meaning 'someone born before') ... at least in relation to the mother and her family." In contrast, one of the midwives I interviewed commented: "At the very beginning I didn't intend to conduct home birth. It was a choice made by the woman. So I decided to help her." Another said: "Women play a leading role and I play a supporting role. Whether in hospital or in a maternity home, an institution will deprive women of initiative. I want both of us to be independent, so I will adhere to home birth." And a third explained, "The reason I make home visits is because I want to observe women's ways of living with my own eyes. I believe women have the ability to give birth themselves and to raise children, so I just want to bring out what they have in them." If a midwife visits a woman's place, then the woman, being in her own territory, feels relaxed, and it becomes easier for her to take the initiative. As one midwife explained, "I am sometimes asked to show how to deliver a breech birth in hospital. But the hospital itself gives women tension. So where and by whom a birth is conducted has a lot to do with the process of birth." Following this line of thought, three out of the seven midwives interviewed for this study chose not to own their maternity homes, preferring to have deliveries occur in women's homes. These ideas about the place of birth indicate that the centralization of birth in the modern period is now being modified by a trend toward decentralization, albeit very slowly.

As for birth position, postmodern midwives think that women should be encouraged to deliver in any position they like; they believe that women themselves instinctively know suitable postures to obtain maximum comfort and safety. Given this kind of latitude, women who choose home births or birth center birth generally do not adopt the supine posture. According to one midwife, "A lot of times women kneel down, her upper part leaning against a bed or her husband and I receive the babies 
from behind. Mothers usually adjust to a comfortable posture themselves so the baby inside comes down smoothly rotating. I don't protect the perineum but tears usually don't occur." Another one said: "In my birth center, statistics show that the kneeling position reduces the amount of bleeding and also the time required for the last part of the second stage." These midwives do not adhere to established ideas. As one of them said: "I want to deconstruct whatever is already established and formalized, whether it be the Lamaze method, water birth, or whatever. I try to respond to what women demand of me."

In sum, the attitude of postmodern midwives, which places higher priority on women's needs and choices than on hospital protocols and traditional methods, reveals that their focus has shifted from maintaining the established medical order to meeting women's needs.

5. Networking, team medicine, and integrative approaches. Having been trained in team medicine in hospital, the midwives I interviewed are accustomed to making decisions through discussions with other midwives and doctors. Even though they make the final decision, they listen to the opinions of others and assess a number of perspectives before deciding. For instance, they do not usually deliver babies alone but ask one or two other midwives to assist them. As one midwife explained: "Birth should be handled with more than one pair of hands. . . . because troubles that occur during childbirth can be major. I think it takes at least two to deal with a delivery and to ensure that the best decisions are made." Another midwife commented, "The reason I ask another midwife for support in delivery is so that we can build a network among ourselves. In doing this I hope to train young midwives in the art of home birth; otherwise I worry that midwifery may go into decline."

In addition to networking with other midwives, postmodern midwives make a great effort to maintain good relationships with medical doctors. They ask women to see a doctor at least once for an antenatal checkup and to have their medical records kept in the doctor's office. One midwife commented:

I have contacts with about 15 doctors as women live in different places. In case of emergency, I need to be able to get in touch with the medical facilities near where the pregnant woman lives. So I ask the 
woman to go and tell the doctor whom she's consulted that she is going to have a home birth with a midwife and that she should ask him or her for help in case of emergency. It is good to surprise doctors with the idea that home birth is now a choice for women. I then accompany the woman to an antenatal checkup and meet the doctor, because I have to sow before I can reap. After the birth, I report the result to the doctor so that she or he will know that home birth with a midwife is a safe choice. By continually establishing this kind of communication one eventually develops a good relationship between doctor and midwife. Many doctors have never worked with midwives on an equal basis and so don't know what our real work involves.

These attitudes toward networking and birth practices encourage postmodern midwives to ignore or to transgress the boundaries maintained by the modernist hospital hegemony, which is characterized by hierarchical oppositions such as hospital/home, doctor/midwife, biomedicine/alternative medicine, and so on. In the postmodern age it has become clear that safety cannot be guaranteed if the priority is to maintain the present hierarchical order -- a priority that often either entails iatrogenic damage to mother and baby or deprives them of necessary medical procedures in cases of emergency. The attitude of postmodern midwives tends to be eclectic and inclusive, moving flexibly between categories according to need (see Introduction, this volume). In Japan, unless independent midwives maintain very good relations with hospital staff it is not easy for them to transport women to hospitals and to continue to care for them.

In addition to incorporating doctors into the home-birth, team-based approach to care, the integrative approach of the postmodern midwife makes use of a wide range of alternative technologies in order to obtain the best outcome. As they are not allowed to offer medical interventions when they practice outside of a hospital, these midwives try as many alternative technologies (e.g. music, aroma, moxibustion, acupuncture, herbal tea, massage, hot water, etc.) as they can.

6. Risk perception and risk management. At a time when obstetrical care is available to anybody at almost any hospital, no midwife will completely rule out the use of medical technology. As one midwife stated: "At a time when many babies were born, people tolerated the idea that, if a baby died, then that 
was its destiny. But now a baby normally stays alive, you can't say a baby died on its own. Safety comes first." She went on to say: "I believe, if you watch a woman closely from the beginning of her pregnancy, that any signs of complication become apparent. So in my case, I do not transfer women to hospital once their labor begins. A woman, if she is able to assume a comfortable position, feels relaxed, and her baby is also relaxed." According to this midwife, the rate of complication and morbidity during labor and delivery is lower at home because women are more relaxed there than they are in hospitals.

During a home birth a midwife must be able to predict risk factors very early on because, legally, she can deal with births only so long as they follow a normal course of progress. In Japan, as midwives are not allowed to obtain or administer any medication without a doctor's consent, they carefully watch for any signs of complications from the very beginning of a woman's pregnancy. They pay close attention to ensure that the woman's condition remains within normal limits because, once it becomes abnormal, the law states that the woman must be entrusted to a doctor. ${ }^{12}$ This does not, however, mean that midwives are incapable of dealing with complications; rather, most of them are quite capable of handling most complications. According to one midwife: "This year [2000] out of 160 births so far, I haven't transferred anybody to hospital. I guess this is because I learned how to give individualized advice to each woman, depending on her personality; if I feel a woman needs to be reminded of something repeatedly, then I tell her many times to, say, watch out for weight gain. And if I feel she needs another piece of advice, then I give it to her. In this way now I ensure that a woman's pregnancy does not drift into the abnormal range."

Hospital-employed midwives can deal with a sudden emergency because they have access to advanced medical technology, while independent midwives must make great efforts to maintain a pregnant woman's stability. The latter predict risk factors at an early stage of pregnancy and tackle them before they develop. For them, risk is something to be calculated and managed.

Research comparing the outcomes for low-risk women who gave birth in hospitals and low-risk women who gave birth in maternity homes shows that the rate of complication and morbidity for both mother and baby is lower in maternity homes (Matsuoka 1995a, Matsuoka 1995b). Given that the rate of complication is higher in hospitals than it is in maternity homes, the argument that birth in the former 
is safer than it is in the latter can be seen to be merely a reflection of the cultural notion that births should occur in hospitals. And this is an ideological rather than a scientific argument. It illustrates a form of hegemony in which hospital and doctors are in authority and maternity homes, women's homes, and midwives are not. In postmodern society, however, this hegemony is weakening, and there are now more places in which it is considered to be acceptable to give birth. Now a decision to give birth in a certain place is increasingly considered to be a matter of personal choice. In pre-modern society there was no choice, home being the only place of delivery; in modern society hospital hegemony, covering up the risks involved in hospital delivery, labeled any birth that occurred in an alternative place a dangerous undertaking; and in postmodern society, although hospital birth is still the norm, the hospital-doctor hegemony is being questioned and challenged as researchers compare data on morbidity and mortality in various birth places (Campbell and Macfarlane 1986; Feldman and Hurst 1987; Fullerton and Severino 1992; Rooks et al. 1992a, 1992b, 1992c; Tew 1986; Sakala 1993; Durand 1992; Matsuoka 1995a, 1995b). In other words, as researchers bring to light the numerous risks pertaining to hospital birth, the risks pertaining to home birth and midwifery care are being shown by the evidence to be relatively low.

As attitudes toward methods of birth change, so do women's attitudes toward their own safety. According to one midwife, "In the past, when giving birth at home was the norm, a woman did not take special care because she was having a home birth. But now women, knowing that they cannot rely on medical interventions at home, try to keep themselves healthy when having a home birth. I think the sense of responsibility and body management on the part of women having home births is different from those having hospital births." In postmodern society, births in different places have been statistically analyzed and compared, and the safety of home births attended by skilled practitioners has been demonstrated (Hazell 1975, Mehl, Peterson et al 1977, Estes 1978, Treffers 1987, Abraham-Van der Mark 1993). Many women are aware of this evidence, and feel confident in the benefits and safety of their choice to birth at home; at the same time, they are aware of their responsibility to make healthy lifestyle choices to minimize risk.

7. Knowledge and skill as commodities. Postmodern midwives are aware of both the necessity 
and the difficulty of converting their professional skills and knowledge into money. As society shifted from pre-modern to modern, the knowledge, skills, and experience of traditional midwives became institutionalized in hospitals. This institutionalization has elevated the status of midwives, giving authority to their skill and knowledge. However, when they became independent and began working outside the hospital, midwives faced the problem of how to charge for their services. In some cases they ended up answering questions by telephone, without even meeting the woman who was seeking advice. According to one midwife: "I often charge for what I say on the phone because I am responsible for the advice I give." Another midwife commented: "It sometimes happens that I give advice by phone and don't charge for it. This can't be helped at the moment. But most of the time I ask a woman if I may visit her in order to better grasp the situation, and I often do end up visiting her." According to a third:

Before becoming independent, I was often asked by some of my neighbors to weigh a baby or to check the mother's breasts. I used to decline offers of money, but now I think I should charge because I shouldn't do the work as a volunteer. Also, in the future there will be younger midwives coming after me. I now charge 5,000 yen for the first visit and 4,000 yen for each subsequent visit. Each visit takes around two hours.

The above story illustrates how the midwife's knowledge may be valued yet not adequately recompensed. The midwives I interviewed charge between 3,000 yen and 4,000 yen for a regular visit, depending on their local economic situations. According to one of them: "If you own a maternity home and employ an assistant midwife, then you need to have more than 60 deliveries a year in order to make a living. In my case I have many clients for breast care, and this makes up for having fewer deliveries." According to another: "I don't employ anybody, nor do I have to pay any rent for my maternity house, so I can manage with only 24 deliveries a year." In this way postmodern midwives, although having different types of practice, manage to market their professional skills outside of institutions.

In pre-modern society knowledge and skills pertaining to childbirth took the form of local cultural 
customs and rituals. In modern society, however, this traditional knowledge was absorbed into institutions, with the consequent professionalization of midwives and institutionalization of birth. As a result, reproductive knowledge and skills, which, to this point, were shared by people in traditional communities, were now possessed by a small number of professional people located in institutions. In postmodern society, however, professional midwives have again returned to local communities.

8. Client access. Some of the postmodern midwives I have interviewed have prepared attractive leaflets that provide such information as location, services, charges, and so on; others do not see the need for such notices. Some give their practice a new name, often including the term "birth center," whereas others use the more traditional "maternity home" (Josan-sho or Josan-in). According to one midwife: "Those who want to give birth at home are eagerly looking for a proper midwife. So whether you advertise or not, people won't come to you just because they see your advertisement; they come by word-of-mouth." Another midwife said: "In the case of a hospital, women choose it for its system or building; but in the case of a maternity home, they choose it for its midwife. They believe in the person, not in the place itself." All of the midwives I interviewed agreed that word-of-mouth communication was extremely important. This suggests that women are willing to trust their friends rather than anonymous sources aimed at a mass market.

Another reason that newspaper or magazine advertisements are not as influential as is personal contact involves the fact that the home birth and midwifery care movements have developed due to the needs of the consumer-cum-client. These are the people who are looking for proper midwifery care and who demand to have a midwife whom they can trust. As was illustrated by the midwife who mentioned that she had decided to help with home births because she was asked to do so, clients often take the initiative and midwives simply cooperate with them. In other words, women are aware of their needs and look for a proper midwife to tend to them.

9. Mobility through technology. Postmodern midwives do not just wait for clients to come to an institution; rather, they get involved in many activities. For example, they visit their clients, respond to requests from other midwives, give talks at antenatal classes, go abroad for seminars, plan events, 
organize mother-baby groups, and so on. Their flexible and varied activities are made possible through automobiles, mobile phones, the Internet, and other communication-transportation networks. One midwife said that she usually finds a 24-hour fast-food restaurant near the woman she is tending and uses that place for resting, waiting for labor to progress, and/or meeting with other midwives. As midwives move from one place to another according to need, they must have the facilities and technology to support this mobility. In postmodern society well-developed communication-information technologies and urban environments ensure that midwives have both flexible activities and high mobility.

\section{The Postmodern Midwife as a Product of Modern Hospital Birth}

Above, I have described the Japanase postmodern midwife in terms of nine characteristics. This form of midwifery is rightly called "postmodern" because the types of practice that have emerged from it have evolved out of and have moved beyond pre-modern and modern forms of midwifery. Japan is unique in that aging independent midwives who assisted in home births still live and practice midwifery (albeit very infrequently); some old women still assist in home birth a few times a year. ${ }^{13}$ Those midwives familiar with pre-modern birth still have some power in midwives' associations and can set an example for younger midwives with regard to such matters as running maternity homes and practicing natural childbirth. Thus, it is possible for postmodern midwives to see both pre-modern independent practice and modern high-tech hospital practice.

It was their observation of hospital births that induced postmodern midwives to leave the institution and work independently. When these midwives worked in hospitals from the 1970s to the early 1990s, obstetrics (with its ultrasound, electronic fetal monitoring, etc.) encompassed almost all normal births. Midwives brought up within this high-tech environment saw their work being fragmented and marginalized. According to one woman: “I wrote many certificates of birth but I don't remember any one of them. I said congratulations to so many mothers, yet I didn't mean it. Everything was just part of the work flow." She described hospital birth as being like "breaking eggs" and said that she had kept thinking something was wrong even though she was acquiring numerous birthing techniques. When she thought of her ideal birth, she felt that the hospital was limited in what it could offer and 
decided that, now that she had learned about various technologies and medications, she could go out on her own.

Hospital birth had created a large number of unfulfilled needs among birthing women, many of whom were looking for available community services. Postmodern midwives catered to the needs of these women. As one woman said: "I used to look after 20 mothers in the postpartum ward, but about half of them had complications such as heart disease or diabetes. All I could do was to observe those high-risk mothers and do nothing for the normal ones. Whether their breasts were swollen or whether the bruises from their episiotomies were painful, I let them go home in five days, wondering what they would do after they got home." Another said: "Women who give birth in my maternity home do not come back due to breastfeeding trouble because they know how to do it; but those who gave birth in hospitals do not know how to keep up breastfeeding and come to me with their troubles." The fact that hospitals discharge women without giving them adequate care, along with the fact that hospital birth by 1998 accounted for 98.8 percent of all births, resulted in a large number of women whose needs were not being met by hospital birth. This may be one reason why, statistically, births attended by an independent midwife increased by 0.2 percent in 1996 (over 1995 numbers), thereby reducing the number of hospital births (Maternal and Child Health Statistics of Japan 1999. Hospital (including clinic) birth occupy $98.8 \%$ in Japan). This may be a sign that services given by postmodern midwives are now known to and welcomed by women who want comprehensive and continuous care from conception through to the postpartum period.

The continued presence of traditional independent midwives played a significant role in the making of postmodern midwives. Those traditional figures adhered to natural childbirth, or "waiting birth," rejecting unnecessary medical intervention. Because this form of birth existed in conjunction with high-tech hospital birth it was possible for midwives to see that technological birth was not the only way; an alternative did exist. Postmodern midwives have learned many of their skills from traditional independent midwives, either through personal acquaintance or through apprenticeship, although they did not model themselves on them entirely. ${ }^{14}$

To conclude, it may be said that postmodern midwifery has come about as a reaction against both hospital birth and traditional midwifery. It may sound paradoxical, but as long as hospital birth is 
mainstream, the need for postmodern midwifery will continue. And it should be obvious that choosing to engage in home birth or maternity home birth negates neither safety nor the use of medical procedures. Women do not opt for home birth because they are ignorant of hospital birth or because they cannot afford it; rather, they choose home birth because they are well-enough informed about hospital birth to make their own assessment and choose other options. We are not looking at a tug of war between the safety of the hospital and the risks of alternative birth places; rather, we are looking at home birth as a woman's attempt to have more than is normally offered in hospitals. In other words, Japanese women go to postmodern midwives because they are concerned with satisfaction, a sense of accomplishment, and care for both their bodies and their emotions; they know that it is difficult to have these wishes met in a hospital environment. Given these realities, it is fair to conclude that postmodern midwifery is a logical consequence of modern hospital birth.

\section{Acknowledgments}

I wish to thank the midwives who spent time answering my questions, and would like especially to thank those seven postmodern midwives whose words I quoted in this article. I also wish to express my gratitude to Mr. Simon Bayley for his encouragement and help in making this article readable.

\section{Notes}

1. The Midwifery (sanba) Regulations of 1899 ruled that:

- those who act as sanba have to be women of 20 years and above who, upon passing sanba examinations, must have their names listed in a registration book.

- those eligible to take prefectural midwife examinations should have more than a year's training prior to doing so. (In reality, a year's training often meant that an applicant only worked as a helper-cum-maid in a doctor's clinic for a year. She did not necessarily have to receive training at a midwifery school.)

- midwives should consult a doctor in cases of abnormal birth.

- midwives should not be involved in abortions.

Later on, those who had graduated from authorized midwifery schools could obtain a license without taking midwife examinations in each prefecture.

2. This number refers to those who were listed in the registration book (i.e. to licensed midwives). The license accounted for two categories of sanba: (1) those who passed midwifery examinations and/or graduated from authorized schools; and (2) those with provisional licenses who were practicing prior to the midwifery regulations of 1899 and were listed in the registration book. Up until 1914 the number of sanba with provisional licenses exceeded the number who had taken medical training.

3.Although the term sanba had long been accepted by the general public, around 1930 it became the focus of dispute among midwives themselves. Some sanba argued that the character 'ba,' meaning old woman, implied being old and outdated and, thus did not properly represent the new educated sanba, who should be distinguished from traditional lay birth attendants. They tried to change their title to san-shi (birth teacher) or to jo-san-shi (help-birth-teacher) by passing the Midwife Bill. Although 
this movement dragged on into the war period, it did not produce any results until 1947, when the title of sanba was officially changed to jo-san-pu (help-birth-woman) as part of the health reform initiated by the GHQ. Japanese midwives, who are all female, are now called josan-pu. Interestingly, the term josan-pu had been used in 1892, when Dr. Ogata founded a midwifery school called Ogata Josan-pu School in Osaka.

4. In those days, midwifery education and nursing education were separate and midwifery students went directly into a midwifery school. In fact, nursing training based on modern medicine started only in 1884 and the nationwide nursing regulation was issued in 1915, 16 years after the Midwife Regulations. It was only after the Second World War that midwifery education and nursing education were combined.

5. By "independent" I mean self-employed. Out of those 2,078 midwives working independently, 805 own their own maternity homes (birth centers), 1,048 conduct home deliveries/visits exclusively, and the rest are employed at maternity homes (Kokumin-eiseino-doko 2000: 178).

6. In Japan maternity homes, or birth centers, are also the homes of the midwives. Midwives allocate some parts of their homes for practice and other parts for family life. They employ other midwives for assistance or to take over in their absence; however, they do not usually engage in group practice on an equal basis.

7. Most of the home-visit-only midwives are entrusted by a municipal government to visit newborn babies and check their health. As this is a part-time job, many old independent midwives switched to home visits only after they had stopped performing deliveries. Some younger midwives, when they were busy raising children, also register for home-visit-only status. There are other home-visit-only midwives who conduct home births without having their own maternity homes.

8. There is another factor that has recently caused midwives to become more aware of their professional identity. In Japan three years of nursing education upon completion of high school, plus one year of midwifery education (by law, midwifery education must be longer than six months), is what is required in order to become a midwife. However, in the last 10 years, nursing education has shifted from three years in nursing school to four years in nursing college or university, where not only nurses, but also midwives and public health nurses, can obtain their qualifications in four years. It is said that the Japanese Nursing Association, to which nurses, community health nurses, and the majority of hospital-based midwives belong, is going to propose a bill to enable graduates of four-year nursing programs to obtain three qualifications (that is, nurse, midwife and public health nurse) under one title -- nurse. Midwives worry that, if this bill gets through Parliament, then the title "midwife" will be lost, as will the right to be independent. The concern is that the midwife will be reduced to a mere obstetric nurse.

Male midwives are currently not allowed to practice in Japan and the issue of whether to allow them divides Japanese midwives. The Japanese Nursing Association, to which most hospital-based midwives belong, strongly supports the idea because the above bill would be impracticable unless male nursing students, too, were eligible to become midwives. However, many independent midwives are uncomfortable allowing men to practice midwifery. The Japanese Midwives Association, though, to which most independent midwives belong, has recently changed its attitude from strong opposition to approval. Many midwives believe that it is part of a wider political attempt to incorporate the title and status of midwife into that of nurse.

9. Although the government began producing medically trained midwives in 1876 and established regulations for midwives in 1899 , this does not necessarily mean that the whole country entered the modern era. Although modern midwifery regulations were set up at the national level during the Meiji era, people's mentality and relationships remained rooted in the pre-modern era. I contend that the basis of pre-modern society is the village community. In Japan, it was only after the Second World War that those village communities were dismantled and that relationships based on community life were replaced by relationships based on the individual. Thus, I assume that, in Japan, the modern era 
began after the Second World War, specifically from the period of rapid economic growth (1955 to 1973). The 1931 case cited below, although it occurred 30 years after the midwifery regulations, is still recognized as exemplary of pre-modern society.

10. In 1885 the first woman doctor was officially registered by the government after completing training of western medicine at school. By 1914 the number of women doctors had risen to 300 and by 1922 to 724 (Nihon-joishi-hensan-iinkai 1962).

11. Although Japanese doctors learned and adopted American ways of birth in the 1950s and 1960s, they were initially uncomfortable with them. In 1952 one doctor, Hayashi, wrote about his experience in an American hospital. When he was present at the delivery of a multipara woman, an American obstetrician made a move to perform an episiotomy. Hayashi tried to stop him, saying that the baby would come soon because it was small. But the obstetrician resisted, almost putting his scissors to the perineum before the baby popped out. A nurse, been accustomed to give the mother ergotrate when the baby's shoulder appeared, did so, even though the baby was already fully born. This made the woman's birth canal contract and prevented the delivery of the placenta. The American obstetrician, being in difficulty, called for his boss, who came in and loudly stated: "It is safer to give forceps after a big episio when a baby is small." Dr. Hayashi concluded that the American way of birth was too standardized and needed some modification (Hayashi 1952:55).

In the same journal, another Japanese doctor wrote: "Americans do not talk about when the use of forceps may be indicated: they do it in every case. They say that forceps appropriately inserted cause less pressure on the fetus's brain than does the natural pressure of the birth canal, thus being less injurious to it. According to them forceps makes birth easier than would be the case in natural childbirth and thus is better for the fetus. I cannot completely understand this way of thinking" (Hashizume 1952:13).

12. In Japan, when a midwife becomes independent she has to register with the local health authority as well as with a back-up doctor in her area (to whom she is supposed to turn to when something abnormal occurs). This does not mean that a midwife always has to transport a laboring woman to this particular doctor. Sometimes, for example, the woman may live far from this doctor or need to be sent to a larger hospital for a c-section. Even though midwives are not officially permitted to make medical interventions, they usually carry such minimum medical equipment as uterine contracting drugs, IV drips, and suturing kits. They can only get this equipment through their back-up doctors as midwives are not legally allowed to buy such medications as ergometrin or methergin without a doctor's permission. This could mean that the relationship between a midwife and a doctor determines the former's scope of practice. According to one postmodern midwife: "Unless you have good relations with your back-up doctor, you can't buy medicine. And even if you can get it somewhere else, then the problem arises as to who permitted you to administer it. If a doctor trusts the midwife to apply certain medicines or equipment, she cannot charge the fee to a patient after using it, because it does not fall within her official scope of practice."

\section{Figure 3 shows the yearly changes of midwives according to place of work since 1952 . This} illustrates that, in Japan, the majority of midwives (about 13,000, or 49 percent) worked independently, assisting births at home or at maternity homes until 1975. According to research conducted in 1962 on independent midwives in Japan, they were 35,179 in number and accounted for 86 percent of all working midwives. As for the age distribution, the 45 to 54 age bracket was the largest, consisting of 36 percent of all midwives, with 79.1 percent of them being over 45 years old and with the average age being 52. This research also indicates that 69 percent of them assisted in less than 10 deliveries, 18 percent assisted in from 11 to 20 , and only 13 percent assisted in more than 21 for the preceding six months. It concludes that independent midwives are decreasing rapidly and that their age is toward the high end (Kosei-tokei-kyokai 1963:125). It can be assumed that, 13 years later, the largest age bracket, the 45-to 54-year-olds, would have reached between 58 and 67, and made up a large number of those 13,000 independent midwives. Figure 4 shows that in 1990 statistics, 31.7 percent of midwives were of the over-60 years of age group who, from their age, were assumed to be traditional independent midwives. 
14. Traditional independent midwives usually put a woman in the supine position when they deliver the baby so that they can carefully watch and protect the perineum in order to prevent any tears. Their ability to protect the perineum is one of the many skills of which these midwives are proud. As they are confident in their own ways of handling birth, they often do not feel the need to change according to new ways of thinking or demands from women. In contrast, postmodern midwives are more flexible and are ready to adapt their attitudes to the demands of laboring women. For example, they do not think that natural childbirth is absolutely best for everybody. The two groups also have different relationships with other midwives: traditional midwives are more competitive, while postmodern midwives are more cooperative, tending to deliver babies with other midwives in attendance.

\section{References}

Abraham-Van der Mark, E.

1993 Successful Home Birth and Midwifery: The Dutch Model. Connecticut and London: Bergin \& Garvey.

Bauman, Z.

1992 Intimations of Postmodernity. London and New York: Routledge.

Bell, D.

1973 The Coming of Post-Industrial Society: A Venture in Social Forecasting. New York: Basic Books.

Bertens, $\mathrm{H}$.

1995 The Idea of the Postmodern: A History. London and New York: Routledge.

Campbell, R. and A. Macfarlane

1986 Place of Delivery: A Review. British Journal of Obstetrics and Gynaecology 93:675-683

Davis-Floyd, R.

1992 Birth as an American Rite of Passage. Berkeley and Oxford: University of California Press.

Durand, A. M.

1992 The Safety of Home Birth: The Farm Study. American Journal of Public Health 82(3):450-453.

Estes, M.

1978 A Home Obstetric Service with Expert Consultation and Back-Up. Birth and the Family Journal $5(3)$

Featherstone, $\mathrm{M}$.

1991 Consumer Culture and Postmodernism. London: Sage.

Feldman, E. and M. Hurst

1987 Outcomes and Procedures in Low Risk Birth: A Comparison of Hospital and Birth Center

Settings. Birth 14(1):18-24.

Fiedler, D.

1997 Authoritative Knowledge and Birth Territories in Contemporary Japan. In Childbirth and Authoritative Knowledge: Cross-cultural Perspectives. R. Davis-Floyd R. and C. F. Sargent, eds. Pp. 159-179. Berkeley and Los Angeles: University of California Press.

Fullerton, J. and R. Severino

1992 In-hospital Care for Low-risk Childbirth: Comparison with Results from the National Birth Center Study. Journal of Nurse-Midwifery 37(5):331-340.

Giddens, A. 
1990 The Consequences of Modernity. Cambridge: Polity.

Hashizume, K.

1952 Amerika-shiki-mutsu-bunben-o-mite (A Thought on American Painless Childbirth).

Sanka-to-fujinka (Obstetrics and Gynecology) 19(1): 11-14.

Hayashi, M. 1952 Osan-nimo-jiyu-o (Freedom to Birth). Sanka-to-fujinka (Obstetrics and Gynecology) 19(1): 55.

Hazell L.

1975 A Study of 300 Elective Home Births. Birth and the Family Journal 2(1).

Ishihara, T. 1983 Josanpu no rekishi 3 (A History of The Midwife 3) Perineitaru-kea (Perinatal Care) 2 (2):113-118.

Itoh, T. 1961 Zadan ninsanpu-hoken-mondai-o-kataru (Discussion on the Care of Pregnant and Laboring Women) Josanpu (The Midwife) 14(1): 8-19.

Iwasaki, $\mathrm{H}$.

1974 Keikaku-bunben (Planned Birth). Sanfujinka-chiryo (Obstetric Treatment) 29(2): 166-170.

Iwata, M.

1968 Sanfujinka-shochino-hensen-o-tadoru (Round Table Talk: Discussion on the Transition of Obstetric Procedures). Sanhujinka-no-sekai (The World of Obstetrician) 20(5): 87-97.

Jameson, F.

1984 Postmodernism, or the Cultural Logic of Late Capitalism. New Left Review 146:53-92.

Kinoshita, S.

1965 Zadan: Shinseiji-no-kanri (A Round Table Talk: Management of the Newborn Baby).

Sanfujink-no-sekai (The World of Obstetricians) 17(7): 29-42.

Kosei-tokei-kyokai (Health and Welfare Statistics Association)

1963 Kokumin-eiseino-doko (Journal of Health and Welfare Statistics) 10(11):125-126.

2000 Kokumin-eiseino-doko (Journal of Health and Welfare Statistics) 47(9): 178.

Kozuka, S.

1975 Keikaku-bunben-no-jissai (How to Make Planned Birth Workable) Sanka-to-fujinka (Gynecology and Obstetrics) 42(3): 13-22.

Kuji, N.

1955 Sanfujinka-Yonjunen (40 years as an obstetrician). Sankato-fujinka (Obstetric and Gynecology) 22(3): 66-70.

Maternal and Child Health Statistics of Japan

1998 ed. Mothers' \& Children's Health \& Welfare Association. P.45.

Matsuoka, E.

1991 Anthropology of Childbirth: Rituals and Midwives. Tokyo: Kaimeisha.

$---$.

1995a Byoinshussan-o-kangaeru (Rethinking the Safety of Hospital Birth) In Asahikawa Ikadaigaku Kiyo (Annual Report of Asahikawa Medical College), vol. 16:33-49. 


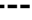

1995b Is Hospital the Safest Place for Birth? In Geb舐en-Ethnomedizinische Perspektiven und Neue Wege. W. Schiefenh • el, D. Sich, and C. Gottschalk-Batschkus, eds. Pp. 293-304. Berlin:

VWB-Verlag $f \cdot$ Wissenchaft und Bildung.

1999 Sanka-kankyou-no-hensen (Changes in Obstetric Procedures:). In

Shussan-zengo-no-kankyou (Environments Surrounding Childbirth), N. Yoshimura, ed. Pp. 142-172. Kyoto: Showado.

Matsuura, T.

1975 Keikaku-bunben-to-iji-hunnsou (Planned Birth and Medical Disputes). Sanka-to-Fujinka (Obstetrics and Gynaecology) 42(3):45-48.

Mehl, L., G. Peterson, et al.

1977 Outcomes of Elective Home Births: A Series of 1146 Cases. The Journal of Reproductive Medicine 19(5).

Moriyama, Y.

1964 Zadan: Jinko-nanzan-o-kataru (A Round Table Talk: On Artificially Induced Complications of Delivery). Sanfujinka-no-sekai (The World of the Obstetrician) 16(9): 93-104.

Nakaoka, T.

1971 Kojo-no-tetsugaku (Philosophy of the Factory). Tokyo: Heibonsha.

Nihon-joishi-hensan-iinkai (Committee for the edition of the history of Japanese women doctors) 1962 Nihon-joi-shi (The History of Japanese Women Doctors). Nihon-joikai-honbu (Japanese Women Doctors Association)

Ohbayashi, M.

1989 Josanpu-no-sengo (After the War Period for the Midwife). Tokyo: Keisoh Shobo.

Ritzer, G.

1996 The McDonaldization of Society. California: Pine Forge Press.

Rooks, J., N. Weatherby, and E. Ernst

1992a The National Birth Center Study. Part 1: Methodology and Prenatal Care and Referrals. Journal of Nurse-Midwifery 37(4):222-253.

$---$

1992b The National Birth Center Study. Part 2: Intrapartum and Immediate Postpartum and Neonatal Care. Journal of Nurse-Midwifery 37(5):301-329.

1992c The National Birth Center Study. Part 3: Intrapartum and Immediate Postpartum and Neonatal Complications and Transfers, Postpartum and Neonatal Care, Outcomes, and Client Satisfaction. Journal of Nurse-Midwifery 37(6):361-397.

Sakala, C.

1993 Midwifery Care and Out-of-Hospital Birth Settings: How Do They Reduce Unnecessary

Cesarean Section Births? Social Science \& Medicine. 37(10):1233-1250.

Shirotono-sanji-toriagekoi-ni-tsuite (On Lay Midwifery)

1932 Josan-to-kango (Midwifery and Nursing) 9(6):14-18. 
Teikokugikai gijiroku Shugiin-iinkai-gijiroku 1934 (Records of Committees of the House of Representatives of the Imperial Diet) Vol. 56, National Diet Library Archives. Reissued by University of Tokyo Press 1994.

Tew, M.

1986 Do Obstetric Intranatal Interventions Make Birth Safer? British Journal of Obstetrics and Gynaecology 93:659-674.

Treffers, P.

1987 Homebirth in the Netherlands. Paper presented at First Homebirth Conference in London.

Tsuno, K.

1965 Zadan: Shinseiji-no-kanri (A Round Table Talk: Management of the Newborn Baby).

Sanfujinka-no-sekai (The World of the Obstetrician) 17(7): 29-42.

Turner, B. S.

1993 Theories of Modernity and Postmodernity. London: Sage.

1995 Medical Power and Social Knowledge. London: Sage.

Yamamura, $\mathrm{H}$.

1961 Zadan: Genka-no-sanka-o-meguru-shomondai-ni-tsuite (Some Current Problems in Obstetrics). Sanfujinka-no-sekai (The World of the Obstetrician) 13(5):133-143.

1966 Bunben-kanshi-sochi-to-sono-mondaiten (The Electronic Fetal Monitor and Its Problems). Sanfujinka-chiryo (Obstetric Treatment) 13(2): 43-45. 
Table 1. Three Phases of Childbirth in Japan

\begin{tabular}{|c|c|c|c|}
\hline & Pre-modern & Modern & Postmodern \\
\hline Mode of production & $\begin{array}{l}\text { Homemade handmade crafts } \\
\text { Primary industry }\end{array}$ & $\begin{array}{l}\text { Mass production of standardized } \\
\text { goods } \\
\text { Secondary Industry }\end{array}$ & $\begin{array}{l}\text { Individualized commodities } \\
\text { Tertiary, quaternary, and quinary } \\
\text { industry }\end{array}$ \\
\hline Mode of reproduction & Home birth & $\begin{array}{l}\text { Hospital birth } \\
\text { Centralization to hospital }\end{array}$ & $\begin{array}{l}\text { Birth in the community } \\
\text { Decentralization }\end{array}$ \\
\hline Birth attendant & $\begin{array}{l}\text { Lay midwife } \\
\text { Licensed independent midwife }\end{array}$ & $\begin{array}{l}\text { Midwife and doctor } \\
\text { Division of Labor } \\
\text { Hierarchy }\end{array}$ & $\begin{array}{l}\text { Independent midwives increase, } \\
\text { although hospital-based midwives and } \\
\text { doctors are in the majority }\end{array}$ \\
\hline Dominant paradigm & $\begin{array}{l}\text { Local custom and ritual } \\
\text { Mutual help }\end{array}$ & Medical science and technology & Choice, autonomy, lifestyle \\
\hline Birth position & Normally vertical & Lying flat on bed & Free style \\
\hline Laboring woman & Neighbor & Anonymous patient & Consumer, client \\
\hline $\begin{array}{l}\text { Ideas about difficu } \\
\text { birth }\end{array}$ & $\begin{array}{l}\text { Misfortune, Random happening } \\
\text { Punishment }\end{array}$ & Hospital birth is safest & $\begin{array}{l}\text { Risk calculation and management } \\
\text { Choice and responsibility }\end{array}$ \\
\hline
\end{tabular}


Table 2. List of Postmodern Midwives in Japan

\begin{tabular}{|c|c|c|c|c|}
\hline \multirow[t]{2}{*}{ Age } & \multirow[t]{2}{*}{$\begin{array}{l}\text { Year } \\
\text { becoming } \\
\text { independent } \\
\text { (age) }\end{array}$} & \multirow[t]{2}{*}{ Location } & \multicolumn{2}{|c|}{ Type of practice } \\
\hline & & & $\begin{array}{l}\text { Number of } \\
\text { deliveries in } \\
\text { 1999(number of } \\
\text { home births) }\end{array}$ & $\begin{array}{l}\text { Breastfeeding support and } \\
\text { other forms of care. Total } \\
\text { number of clients per } \\
\text { month* }\end{array}$ \\
\hline $4 \odot$ & 1990 & Ishikawa Pref. & $45(0)$ & 120 \\
\hline 41 & 1994 & Hokkaido & $(4)$ & 70 \\
\hline 55 & 1988 & Hokkaido & $150(10)$ & A few \\
\hline 46 & 1990 & Saitama Pref. & $160(5)$ & 30 \\
\hline 48 & 1997 & Sapporo & $24(22)$ & 10 \\
\hline 48 & 1986 & Tokyo & $(60)$ & A few \\
\hline 55 & 1987 & Tokyo & $206 \quad(22)$ & A few \\
\hline
\end{tabular}

* These figures exclude the check-ups (e.g., postpartum care for five consecutive days, one-month postnatal care) given to mothers who were delivered by these midwives. 